\title{
Chemical Composition of Exopolysaccharides of Rhizobium and Agrobacterium
}

\author{
By L. P. T. M. ZEVENHUIZEN \\ Laboratory of Microbiology, Agricultural University, \\ Wageningen, The Netherlands
}

\section{(Accepted for publication 27 July 197I)}

Hopkins, Peterson \& Fred (1930) found glucose and glucuronic acid as constituents of the exopolysaccharides of Rhizobium meliloti, $R$. trifolii and $R$. leguminosarum; Schlüchterer \& Stacey (1945) investigated the structure of the exopolysaccharide of $R$. radicicolum (Clover Bartel A strain) by methylation. Subsequently, composition was studied in relation to taxonomy (Humphrey \& Vincent, 1959; Graham, 1965) and to antigenic properties(Dudman, 1964). Ljunggren \& Fåhraeus (1959) studied the effect of exopolysaccharides on root-hair invasion by rhizobia, while Clapp, Davis \& Waugaman (I962) used Rhizobium exopolysaccharides as model compounds for studying the importance of polysaccharides in crumb stability of soils.

Various attempts have been made to relate the exopolysaccharide composition of Rhizobium strains with their specificity in cross-inoculation groups. In a qualitative chemical analysis of exopolysaccharides of Rhizobium leguminosarum, $R$. trifolii and $R$. phaseoli, Humphrey \& Vincent (1959) found both glucose and glucuronic acid, while strains of $R$. meliloti were found to contain only glucose. Besides glucose (66\%), Dudman (1964) detected galactose (12\%) and smaller amounts of unidentified sugars in hydrolysates of R. meliloti polysaccharides (two strains). The same components were also found in Io strains of $R$. meliloti by Amarger, Obaton \& Blachère (1967). However, Clapp \& Davis (1970) concluded that polysaccharide analysis has only limited value for classification of Rhizobium. When testing several cultures of various groups they did not find a direct relationship between host legume and constituent sugars.

\section{METHODS}

In this study the exopolysaccharide composition of Rhizobium and Agrobacterium has been examined, using 2 I strains from five taxonomic groups. Strains were taken from the culture collection of the laboratory; they had different origins and were all infective in the host legume of their own group.

Cultivation of organisms. Bacterial strains were kept on slants of the following medium: yeast extract, $0.1 \%$; mannitol, I \% $\mathrm{K}_{2} \mathrm{HPO}_{4}, 0.05 \% ; \mathrm{MgSO}_{4} .7 \mathrm{H}_{2} \mathrm{O}, 0.025 \% ; \mathrm{NaCl}$, $0.0 \mathrm{I} \% ; \mathrm{CaCO}_{3}, 0.3 \%$; agar, $\mathrm{I} \cdot 2 \%$. This medium was also used to grow the organisms in Petri dishes. For larger quantities of bacteria a liquid medium of the following composition was used: mannitol, I \%; glutamic acid, 0.I \%; $\mathrm{K}_{2} \mathrm{HPO}_{4}, 0 . \mathrm{I} \% ; \mathrm{MgSO}_{4} \cdot 7 \mathrm{H}_{2} \mathrm{O}, 0.02 \%$; $\mathrm{CaCl}_{2}, 0.004 \%$; biotin, Io $\mu \mathrm{g} . / 1$; thiamin, I00 $\mu \mathrm{g}$. $/ 1$; trace elements: $\mathrm{FeCl}_{3} .6 \mathrm{H}_{2} \mathrm{O}, 2.5$; $\mathrm{H}_{3} \mathrm{BO}_{3}$, 0.0I; $\mathrm{ZnSO}_{4} \cdot 7 \mathrm{H}_{2} \mathrm{O}$, 0.0I; $\mathrm{CoCl}_{2} .6 \mathrm{H}_{2} \mathrm{O}$, 0.0I; $\mathrm{CuSO}_{4} .5 \mathrm{H}_{2} \mathrm{O}, 0.0 \mathrm{I} ; \mathrm{MnCl}_{2}$, I ; $\mathrm{Na}_{2} \mathrm{MoO}_{4} \cdot 2 \mathrm{H}_{2} \mathrm{O}$, o.oI mg./1. Salts and other nutrients were dissolved in distilled water and adjusted to $\mathrm{pH} 6.7$ with $\mathrm{NaOH}$. Organisms were grown in $100 \mathrm{ml}$. of the above synthetic 
mannitol-glutamic acid medium, contained in $300 \mathrm{ml}$. Erlenmeyer flasks, and aerated on a rotary shaker at $25^{\circ}$ for 5 days.

Preparation of exopolysaccharides. After cultivation the bacteria were harvested from the plates and suspended in water. The suspensions and liquid cultures were centrifuged at $40,000 \mathrm{~g}$ for $\frac{1}{2} \mathrm{~h}$., followed by dialysis of the supernatant against distilled water. Isolation of the polysaccharide was achieved by adding three volumes of ethanol to the clear supernatant, centrifuging, redissolving in water, and dialysing against running water for $48 \mathrm{~h}$. These procedures did not remove all impurities. With highly viscous polysaccharide solutions it was difficult to remove all bacteria completely by centrifugation. Sometimes dilution with water prior to centrifugation, or filtration over a filter aid (celite) was more successful. The soluble protein content, as determined by the method of Lowry, Rosebrough, Farr \& Randall (I95I), usually was lower than I \%. All preparations contained amounts of ash from the bound cations of the acidic groups in the polysaccharide.

Quantitative chemical analysis of exopolysaccharides of Rhizobium and Agrobacterium. Exopolysaccharides were hydrolysed with $0.5 \mathrm{M}-\mathrm{H}_{2} \mathrm{SO}_{4}$ in sealed ampoules at $100^{\circ}$ for $16 \mathrm{~h}$. The hydrolysates were neutralized with barium hydroxide and centrifuged, followed by deionization of the supernatant over IR-I 20 resin ( $\mathrm{H}^{+}$-form). Component sugars were separated on Whatman no. I paper, using $n$-butanol-pyridine-benzene-water, 5:3:I:3 (v/v), and sprayed with $p$-anisidine-HCl.

\section{RESULTS AND DISCUSSION}

Paper chromatograms of polysaccharide hydrolysates showed glucose as the main component. Galactose was always present as a minor component, while in some cases small amounts of mannose were found. Non-uronic acid containing polysaccharides (Rhizobium meliloti and Agrobacterium tumefaciens) gave nearly quantitative yields of reducing sugars with no detectable, incompletely hydrolysed fragments on paper chromatograms. Moreover, uronic acid containing polysaccharides yielded glucuronic acid and aldobiouronic acid(s) in combination with a fast running spot of glucuronolactone. These aldobiouronic acid(s) could not be completely hydrolysed, even after prolonged hydrolysis for 24 h. in $\mathrm{M}_{2}-\mathrm{H}_{2} \mathrm{SO}_{4}$. Consequently, the total amount of hexoses, as determined with anthrone, could not entirely be recovered as the sum of free glucose + galactose in the hydrolysate ( 90 to $95 \%$ recovery). 4- $O$-methylglucuronic acid, which was found in polysaccharide hydrolysates of $R$. trifolii, $R$. leguminosarum and $R$. phaseoli by Graham (I965) and Humphrey (1959) as a fast-running spot on paper chromatograms, could not be found in the present investigation.

Pyruvate and $O$-acetyl were present as non-carbohydrate components in all preparations tested. They were identified by chromatographic analysis of the 2,4-dinitrophenylhydrazones in benzene-ethyl acetate $(8: 2, \mathrm{v} / \mathrm{v})$, and by chromatography of the hydroxamates in ethyl acetate-acetic acid-formic acid-water $(18: 3: 1: 4, v / v)$ respectively, using the appropriate standards.

The results of the quantitative chemical analyses of exopolysaccharides of Rhizobium and Agrobacterium are summarized in Table I. Weight percentages of the components were calculated on the sum of all components determined (glucose + galactose + uronic acid + pyruvate + acetyl). A distinctive difference can be observed between the groups of Rhizobium leguminosarum, R. phaseoli, and R. trifolii, and the groups of $R$. meliloti and Agrobacterium tumefaciens. The first three groups of Rhizobium polysaccharides all had the same range of glucose ( 48 to $6 \mathrm{I} \%$ ), galactose ( 8 to $14 \%$ ), glucuronic acid (I 4 to $19 \%$ ), pyruvate (Io to I $5 \%$ ) and acetyl ( 7 to I $3 \%$ ). R. meliloti and $A$. tumefaciens polysaccharides showed a much 
higher content of glucose $(76$ to $83 \%$ ) and contained less than I \% glucuronic acid; pyruvate ( 3 to $8 \%$ ) was lower than with the first three groups of rhizobia. Dudman \& Heidelberger (1969), who were the first to prove the presence of non-carbohydrate components in Rhizobium exopolysaccharides, found 9 to $10 \%$ pyruvic acid and 3 to $4 \%$ acetyl in air dried

\section{Table I. Quantitative chemical analysis of exopolysaccharides of Rhizobium and Agrobacterium}

The first number refers to exopolysaccharide of bacteria grown on yeast extract-mannitol-agar plates; the second number, in a liquid mannitol-glutamic acid medium.

\begin{tabular}{|c|c|c|c|c|c|}
\hline \multirow[b]{2}{*}{ Strain } & \multicolumn{5}{|c|}{ Component $(\%)$} \\
\hline & Glucose* & Galactose* & Uronic acid $\dagger$ & Pyruvate $\ddagger$ & Acetyl§ \\
\hline \multicolumn{6}{|c|}{ Rhizobium leguminosarum } \\
\hline H VIII & 48,53 & II, IO & 19,14 & 14,15 & 8,8 \\
\hline P-8 & 48,61 & II, 9 & 19,14 & 13,10 & 9,6 \\
\hline PRE & $48,5 \mathrm{I}$ & II, 9 & 19,19 & I3, I I & 9,10 \\
\hline 310 & 51 & 9 & 16 & 15 & 9 \\
\hline $3 / 3$ & 46,49 & I4, 13 & 14,18 & I 5 , I I & II, 9 \\
\hline 402 & 49,50 & 10,10 & 16,19 & 15,13 & 10,8 \\
\hline 404 & 49,50 & I0, 9 & 17,18 & 14,13 & IO, IO \\
\hline \multicolumn{6}{|l|}{ R. phaseoli } \\
\hline Blink & 48,56 & II, 9 & 16,17 & 13,10 & 12,8 \\
\hline 460 & 50,54 & 10, 9 & 17,21 & I I, I 2 & 12,5 \\
\hline . & 50,59 & 9,8 & 18,16 & 14, I I & 9,6 \\
\hline \multicolumn{6}{|l|}{ R. trifolii } \\
\hline & 48 & IO & 13 & 15 & 14 \\
\hline In? & 49,50 & II, I9 & 17,14 & I3, Io & 10,7 \\
\hline In 2 & 50,50 & 10,10 & 18,19 & I2, I I & IO, IO \\
\hline $\mathrm{K}-8$ & $5 \mathrm{I}, 5 \mathrm{I}$ & II, 9 & 16,20 & I I, I I & I I, 9 \\
\hline \multicolumn{6}{|l|}{ R. melilgh } \\
\hline BPy & 77,76 & Io, 9 & $0, \quad \mathbf{I}$ & 5,7 & 8,7 \\
\hline$h-2$ & 75,76 & 8,8 & $2, \quad I$ & 6,6 & 9,9 \\
\hline A-I 45 & 83,79 & 8,9 & $0, \quad I$ & 3,6 & 6,5 \\
\hline A-I 48 & 74,78 & I 2,9 & $0, \quad I$ & 5,6 & 9,6 \\
\hline \multicolumn{6}{|c|}{ Agrobacterium tumefaciens } \\
\hline A-8 & 78,80 & IO, 10 & 0,2 & 7,6 & 5,2 \\
\hline A-9 & 77,76 & Io, I I & $0, \quad I$ & 8,7 & 5,5 \\
\hline A-IO & $77,8 \mathrm{I}$ & II, IO & 0,0 & 8,6 & 4,3 \\
\hline
\end{tabular}

* Glucose and galactose in the hydrolysate were measured with glucose oxidase and galactose oxidase reagents (Kabi, Stockholm, Sweden) respectively.

$\dagger$ Uronic acid content was measured with the modified carbazole reaction (Bitter \& Muir, I962) using glucuronolactone as a standard and corrected for interference by hexoses.

† Pyruvate was measured according to a modification of the method of Sloneker \& Orentas (Sutherland, 1969).

$\S O$-acetyl measurements were carried out according to Hestrin (1949) using glucose penta-acetate as a standard.

samples of $\boldsymbol{R}$. trifolii polysaccharides. These results are in agreement with the present data when expressed on a dry weight basis. They also found a much lower pyruvic acid content for $R$. meliloti (approx. $5 \%$ ).

Quantitative data on sugar composition were until recently very scarce. Amarger, Obaton \& Blachère (1967) found a close similarity in percentage composition of polysaccharides of to strains of Rhizobium meliloti. After hydrolysis in $0.5 \mathrm{M}-\mathrm{H}_{2} \mathrm{SO}_{4}$ at $100^{\circ}$ for $6 \mathrm{~h}$., the percentage of the total sugars varied from 82 to $86 \%$ for glucose, 13 to $16 \%$ for 
galactose and 0.4 to $\mathrm{x} \cdot 2 \%$ for glucuronic acid, suggesting a homogeneity of the polysaccharides of this group of Rhizobium.

On the contrary, Clapp \& Davis (1970) found wide variations in chemical composition between 18 strains of Rhizobium of different groups. They found as many differences within a single host legume group as between groups. Uronic acid, after separation from neutral sugars on anion exchange resin, ranged from o to $22 \%$. No direct relationship between uronic acid content and host legume was found. Moreover, their ratios of total carbohydrate/uronic acid showed a wide range, in contrast with the nearly constant ratio of 3 to 4 for the uronic acid containing preparations of Table $\mathrm{I}$. Their preparations were obtained by cultivation of the bacteria in complex yeast extract-mannitol medium. In the present investigation organisms were grown in a synthetic medium (mannitol-glutamic acid) or on agar surfaces of a complex medium (yeast extract-mannitol) in order to avoid contamination of the polysaccharide preparations by polymeric carbohydrate of the medium. Hexoses and uronic acids were directly determined in the polysaccharide hydrolysates with anthrone and carbazole respectively, and corrected for interference by the other component.

Concluding, it can be said that Rhizobium leguminosarum, $R$. phaseoli and $R$. trifolii form a homogeneous and indivisible group, differing from $R$. meliloti and Agrobacterium tumefaciens, which were very similar. These results are consistent with earlier reports in which taxonomy was studied by application of computer techniques (Graham, I964) and by DNA base composition and flagellation (DeLey \& Rassel, 1965).

I wish to acknowledge the technical assistance of Miss Anneke Ebbink, who carried out most of the chemical analyses of polysaccharides.

\section{REFERENCES}

Amarger, N., Obaton, M. \& Blachère, H. (1967). Polysaccharides extracellulaires de Rhizobium meliloti. Canadian Journal of Microbiology 13, 99-105.

Prtter, T. \& MuIR, H. M. (1962). Modified uronic acid carbazole reaction. Analytical Biochemistry 4, 330334.

ClaPP, C. E. \& Davis, R. J. (1970). Properties of extracellular polysaccharides from Rhizobium. Soil Biology and Biochemistry 2, ro9-II7.

Clapp, C. E., Davis, R. J. \& Waugaman, S. H. (I962). The effect of rhizobial polysaccharides on aggregate stability. Proceedings Soil Science Society of America 26, 466-469.

DeLey, J. \& RASSEL, A. (I965). DNA base composition, flagellation and taxonomy of the genus Rhizobium. Journal of General Microbiology 4r, 85-91.

Dudman, W. F. (1964). Immune diffusion analysis of the extracellular soluble antigens of two strains of Rhizobium meliloti. Journal of Bacteriology 88, 782-794.

Dudman, W. F. \& Heidelberger, M. (1969). Immunochemistry of newly found substituents of polysaccharides of Rhizobium species. Science, Washington I64, 954-955.

Graham, P. H. (1964). The application of computer techniques to the taxonomy of the root-nodule bacteria of legumes. Journal of General Microbiology 35, 5I I-5I 7 .

Graham, P. H. (1965). Extracellular polysaccharides of the genus Rhizobium. Anthonie van Leeuwenhoek 3r, 349-354.

Hestrin, S. (1949). The reaction of acetylcholine and other carboxylic acid derivatives with hydroxylamine, and its analytical applications. Journal of Biological Chemistry r8o, 249-261.

Hopkins, E. W., Peterson, W. H. \& Fred, E. B. (1930). Composition of the gum produced by root nodule bacteria. Journal of the American Chemical Society 52, 3659-3668.

HumphreY, B. A. (1959). Occurrence of 4-O-methylglucuronic acid in Rhizobium gums. Nature, London I84, 1802 .

Humphrey, B. A. \& Vincent, J. M. (1959). Extracellular polysaccharides of Rhizobium. Journal of Genera Microbiology 21, 477-484. 
LJUNGGREN, H. \& FÅHRaeus, G. (1959). Effect of Rhizobium polysaccharide on the formation of polygalacturonase in lucerne and clover. Nature, London 184, I578-1579.

Lowry, O. H., Rosebrough, N. J., Farr, A. L. \& Randall, R. J. (195I). Protein measurements with the Folin phenol reagent. Journal of Biological Chemistry 193, 265-275.

SCHLÜCHTERER, E. \& STACEY, M. (I945). The capsular polysaccharide of Rhizobium radicicolum. Journal of the Chemical Society, 776-783.

SutherLAND, I. W. (1969). Structural studies on colanic acid, the common exopolysaccharide found in Enterobacteriaceae, by partial hydrolysis. Biochemical Journal 115, 935-945. 